\title{
The influence of communication technologies and approaches to study on transactional distance in blended learning
}

\author{
Steve Wheeler* \\ University of Plymouth, UK
}

\begin{abstract}
This paper explores the role played by communication technologies and study orientations in the amplification and reduction of transactional distance in blended learning. Factor analysis and structural equation modelling of different communication modes (face to face, email and telephone) revealed that students experience at least some transactional distance when separated from their tutors. Email was found to facilitate the highest levels of immediacy of dialogue for most students. The conclusion is that strategic students are best placed to benefit from blended learning, and that the effects of transactional distance could be analysed more deeply if two subvariables of dialogue were recognised. These are social presence (the perception of connectedness between students and their tutors) and immediacy (the temporal effects of dialogue).
\end{abstract}

\section{Introduction}

Learning technologies can provide 'any time, any place' learning opportunities (Wheeler \& Vranch, 2001). Reflecting this trend, the term 'blended learning' describes incorporation of distance and local learning activities. Improved communication bandwidth and greater access to computers have blurred the boundaries of contemporary practice. Consequently, the term 'distance education' may now be redundant, as geographical distance should no longer be a barrier between teacher and learner (Dabbagh, 2004). Instead, gaining a better understanding of psychological distance may hold the key to the successful teaching of distributed students.

Perceptual distances have profound effects on learners who are separated for long periods from their tutors. One-half of all distance learners fail to complete their

\footnotetext{
*Faculty of Education, University of Plymouth, Drake Circus, Plymouth PL4 8AA, UK. Email: S.Wheeler@plymouth.ac.uk
} 
studies (Ross et al., 1991; Moore \& Kearsley, 1996; Simpson, 2004). Lack of dialogue may heighten perceptions of distance, which may contribute toward such poor retention rates (Dron et al., 2004). Perceptual distance should therefore assume importance as a research focus. The means through which perceptual distance can be empirically measured and analysed constitutes the methodological basis of this study. Moore's (1973) theory of transactional distance was applied as an explanatory framework, with perceptual distance predicted by the variables of dialogue, structure and student autonomy. The study utilised Entwistle's (1981) Approaches to Study Inventory and two additionally devised Likert-scale inventories to measure the variables predicted to influence transactional distance. Structural equation modelling was applied to enable visualisation of the relationships between these variables, and to assess the statistical power and validity of the research findings.

\section{Transactional distance theory}

According to transactional distance theory (Moore, 1993), perceptual distance is present in every educational transaction. The transactional distance between student and tutor, whether based upon perceptions of intellectual differentials, demographic variables such as age or gender, or cultural distances such as language, may create the potential for misunderstandings to occur.

Transactional distance theory predicts that psychological distance between students and tutors varies as a result of the structure and dialogue mix within transactions. If structure is high, dialogue decreases; whereas if dialogue is high, structure decreases. Moore's theory predicts that greater presence of dialogue in the learning transaction should reduce transactional distance, engender better understanding and lessen the potential for misunderstandings to occur. This study focuses on how communication technologies may mediate psychological distance. Blended learning communication is represented across three modalities - the baseline measurement of face-to-face communication, and two distance-based technologies: telephone and email.

\section{Research hypotheses}

The study set out to explore two hypotheses.

The first was that students whose dialogue with their tutors is mediated by technology should report greater (i.e. more remote) transactional distance than students whose dialogue with their tutors is conducted through face-to-face communication, due to the reduction of social cues and a decrease or inhibition in the richness of communication that would normally be expected to be present in face-to-face dialogue. Such reductions should amplify the potential for misunderstandings to occur and for a raised perception of distance due to a lessening of social presence.

The second hypothesis was that distance learners should report greater transactional distance of communication with their teacher if dialogue is mediated through asynchronous text-based technologies. This may result in less satisfaction with the 
learning experience due to a greater potential for misunderstandings to occur. Where synchronous technologies are employed, distance learners should report less (i.e. closer) transactional distance, leading to the potential for less misunderstanding to occur during dialogue. This could be due to the tendency of synchronous forms of communication to sacrifice structure in favour of greater dialogue. Synchronous technologies were also thought to provide more immediacy of dialogue, providing remote students with rapid support and guidance.

\section{Sample}

In an opportunistic sample, 348 students enrolled on a variety of continuing professional development courses for teachers participated in the study. The participants studied across a broad spectrum of study modes mixing face-to-face on-campus learning with varying amounts of directed study undertaken both at home and in the workplace.

Participants were predominantly female, with 307 females and 38 males in the sample (three participants declined to report their gender) (Table 1). This gender bias is consistent with similar recent studies where females constitute the largest percentage of students studying on humanities-based and liberal arts-based courses, such as teaching in the United Kingdom (Goodyear et al., 2003). As is common in continuing professional development, the sample was predominantly mature, comprised mainly of fully employed, part-time students.

\section{Method}

Participants completed a five-point Likert-scale questionnaire, containing Entwistle's (1981) Approaches to Study Inventory, the Student Support Inventory (Wheeler, 2002) and the Communication Mode Questionnaire (see http:// www2.plymouth.ac.uk/distancelearning/). The Student Support Inventory measured students' perceptions of expected and received support and the Communication Mode Questionnaire measured perceptions of dialogue, structure and transactional distance in different communication modes. Data were collected over a two-and-ahalf-year period, as each student cohort commenced study. The questionnaire also contained demographic questions, and asked about expected tutor support.

Table 1. Participant sample descriptive data

\begin{tabular}{|c|c|c|c|c|c|c|c|c|}
\hline & \multirow[b]{2}{*}{ Male } & \multirow[b]{2}{*}{ Female } & \multirow[b]{2}{*}{$\begin{array}{l}\text { Missing } \\
\text { data }\end{array}$} & \multicolumn{2}{|c|}{ Age (years) } & \multicolumn{3}{|c|}{$\begin{array}{l}\text { Number of questionnaire } \\
\text { respondents for each mode }\end{array}$} \\
\hline & & & & Mean & $\begin{array}{l}\text { Standard } \\
\text { deviation }\end{array}$ & $\begin{array}{l}\text { Face to } \\
\text { face }\end{array}$ & Email & Telephone \\
\hline Total & 38 & 307 & 3 & 40.8 & 8.15 & 237 & 85 & 72 \\
\hline
\end{tabular}




\section{Structural equation modelling}

The first stage of the structural equation modelling process required the creation of a model that would represent the theoretical interrelationships between the proposed variables of structure, dialogue and study approaches in all three modes of communication. Through factor analysis, a first-order path model was constructed comprising of three latent variables.

\section{Exogenous model}

Figure 1 represents the proposed full 'three-factor' exogenous model. The ovals represent the three latent variables, while the rectangles represent the questionnaire items as observed, dependent variables that contribute to the latent variables. This was a theoretical model used as a template for the actual data, enabling visualisation of the potential relationships between observed and latent variables (factors).

Following confirmatory analysis using EQS software, one item was removed from the model (ASI11B - relating new learning to 'real life') as its inclusion reduced goodness of fit. The revised full three-factor model for approaches to study is illustrated in Figure 2 complete with estimated factor loadings.

Single-headed arrows show standardised factor loadings, and double-headed arrows represent the inter-factor correlations. The double-headed arrow joining two of the variables on the extreme left of the model indicates a correlation between two error terms. Factor loadings are equivalent to standardised regression beta coefficients, which were estimated using maximum likelihood estimation (Miyake et al., 2000).

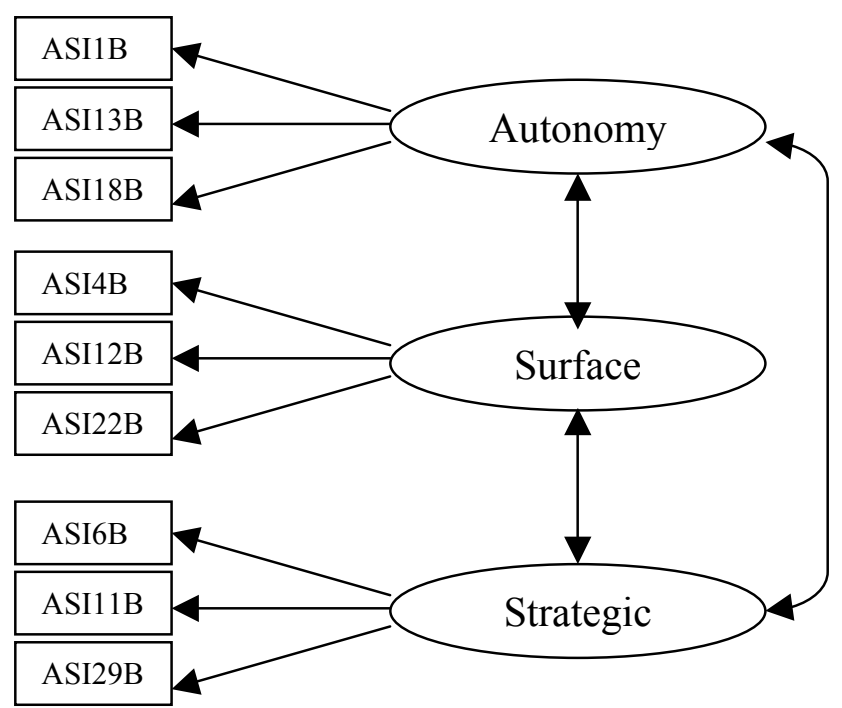

Figure 1. Theoretical full three-factor model used for confirmatory factor analysis 


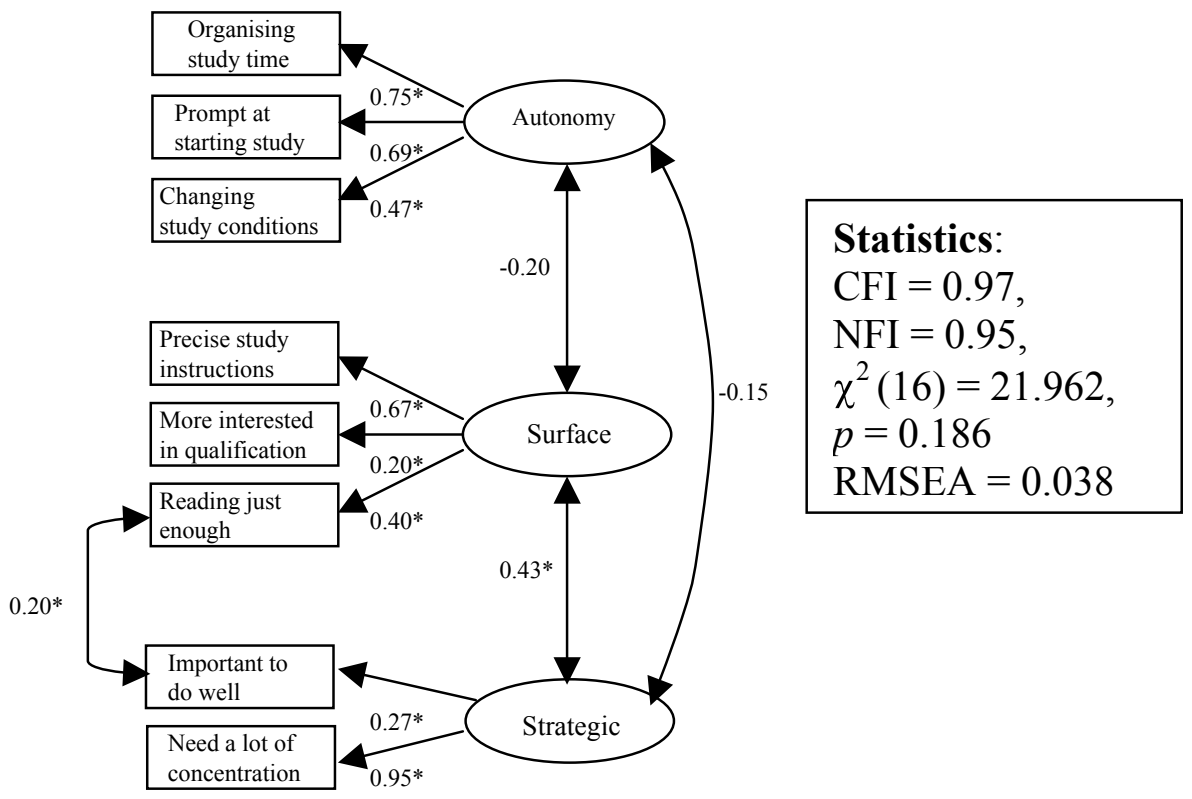

Figure 2. Revised full three-factor face-to-face model with standardised solution

Factor loadings, correlations and beta coefficients significant at the 0.05 level and below are indicated by asterisks. The fit indices for this revised model were within acceptable limits, producing a statistically non-significant $\chi^{2}(16)=21.962, p<$ 0.186 , indicating that the model's predictions did not significantly deviate from the expected data pattern. The comparative fit index $(\mathrm{CFI}=0.97)$ and the normed fit index $(\mathrm{NFI}=0.95)$ were clearly above the generally accepted cut-off point of 0.90 (Byrne, 1994).

Strategic approaches to study do not preclude the use of surface approaches if required; for example, during intense revision for an impending written examination. This may explain the significant correlation between the surface and strategic factors $(r=0.43, p<0.05)$. Strategic learners can manage their own personal study routines better, and require less tutor input, developing skills to manage course content and monitor their own progress. They have better self knowledge and know how to evaluate the outcomes of their own learning to inform themselves of future directions for study (Weinstein \& Van Mater Stone, 1996). The strategic label was thus applied to the factor explaining the revised items grouping.

\section{Endogenous model}

The factor structure for the first theoretical model represents the face-to-face modality of communication between student and tutor, and also by extension the other communication modalities to be tested. 
The second factor is an aspect of dialogue, based upon the work of Shin (2003), and represents transactional presence. The third and final factor represents items related to immediacy, a proposed affordance of the technology mediated process of dialogue between teacher and student.

The one-way arrows between factors represent the strength and direction of the assumed causal relationships between latent and dependent variables, and are measured as regression or beta coefficients. The two-headed arrows are correlations, indicating the strength of association between the latent variables.

The next stage in the structural equation modelling process was to fit the complete model together by combining the exogenous model together with an endogenous model into a full face-to-face modality pathway matrix and then running a third, general, model fit analysis as shown in Figure 3.

The EQS software analysis showed that the chi-squared value was statistically nonsignificant, at $\chi^{2}(28)=39.301, p=0.145$, indicating that the model's predictions did not transgress data pattern boundaries. Both the CFI (0.98) and NFI (0.98) were above the recommended 0.95 limit and were thus deemed acceptable. The Root Mean Square Error of Approximation (RMSEA) value achieved a good fit at 0.50 so the model was accepted as the baseline face-to-face model and used for all subsequent comparisons between communication modes. Error terms and correlations were omitted from the above path model diagram to simplify its presentation. Similar models were created to represent participants' perceptions when using telephone or email. All data from these path models are found in Table 2.

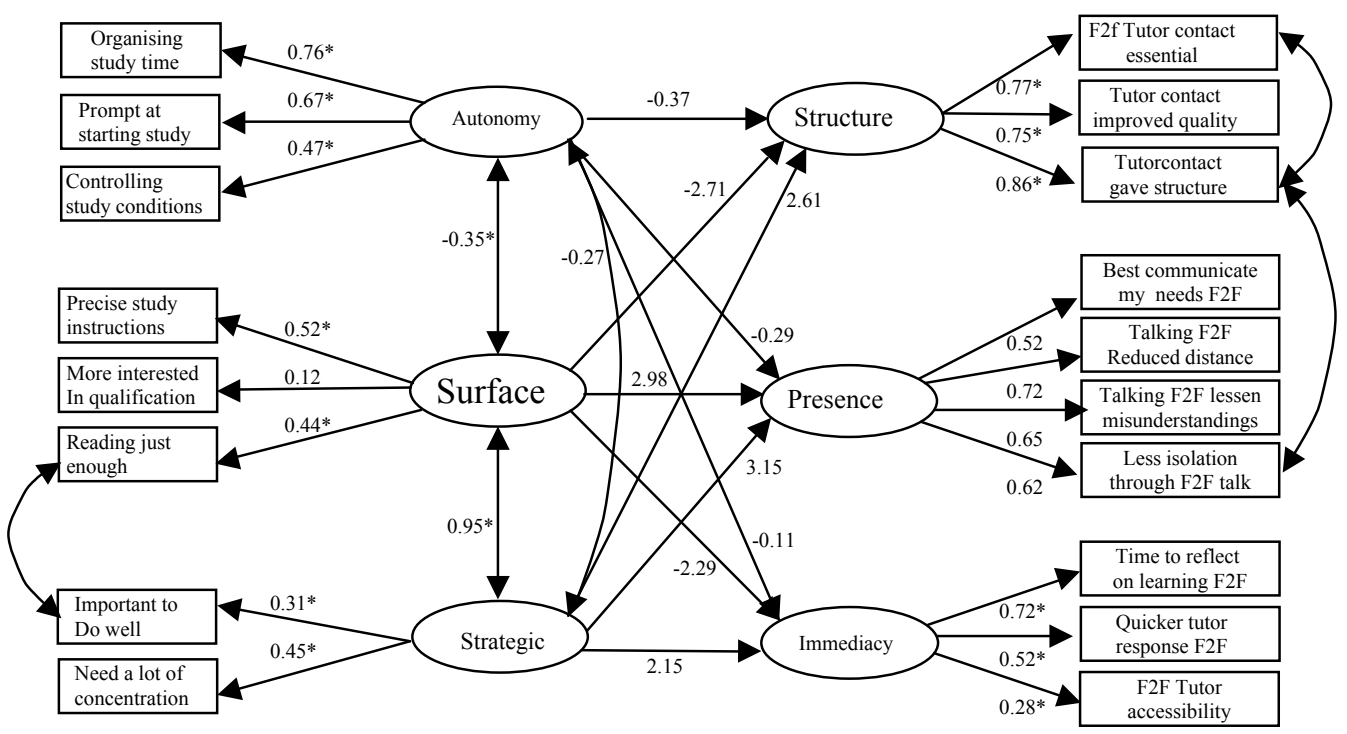

Figure 3. Structural equation model (modality model: face to face) $\chi^{2}(120)=171.08, p<0.001$, $\mathrm{CFI}=0.92, \mathrm{RMSEA}=0.05$. 
Table 2. Summary of coefficients

\begin{tabular}{lccc}
\hline Factor pathway & Face to face & Telephone & Email \\
\hline Exogenous factor correlations & & & \\
$\quad$ Autonomy/strategic & -0.27 & 0.15 & -0.09 \\
Autonomy/surface & $-0.35^{\star}$ & -0.29 & - \\
Strategic/surface & $0.95^{\star}$ & $0.69^{\star}$ & - \\
Regression $(\beta)$ coefficients to endogenous factors & & & \\
Autonomy/structure & -0.37 & -0.24 & $0.32^{\star}$ \\
Autonomy/presence & -0.29 & -0.25 & $0.31^{\star}$ \\
Autonomy/immediacy & -0.11 & -0.14 & $0.49^{\star}$ \\
Strategic/structure & 2.61 & $0.92^{\star}$ & $0.98^{\star}$ \\
Strategic/presence & 3.15 & 1.36 & $0.92^{\star}$ \\
Strategic/immediacy & 2.15 & 1.36 & $0.77^{\star}$ \\
Surface/structure & -2.71 & $-0.75 \star$ & - \\
Surface/presence & 2.98 & -1.45 & - \\
Surface/immediacy & -2.29 & -1.26 & - \\
$\chi^{2}$ & $171.08^{\star \star}$ & 144.27 & $169.51^{\star \star}$ \\
Degrees of freedom & 120 & 119 & 127 \\
$\chi^{2} /$ degrees of freedom & 0.09 & 1.21 & 1.33 \\
RMSEA & 0.05 & 0.05 & 0.06 \\
CFI & 0.92 & 0.94 & 0.93 \\
\hline
\end{tabular}

Significant at ${ }^{\star} p<0.05$ and ${ }^{\star \star} p<0.01$.

\section{Results}

The full baseline pathway model for face-to-face tutor support represents student perceptions of course structure, social presence, and immediacy of dialogue. Of these endogenous factors, the first represents Moore's concept of 'structure' and is measured through student evaluations of how important they perceived tutor contact, and whether this contact improved the quality of course delivery. Also contributing to the factor of structure is the extent to which student felt dialogue with the tutor imposed structure upon their learning. The second factor of social 'presence' representing students' perceptions of connectedness to their tutors is derived from their responses to questions relating to how they could best communicate their study needs, their perceptions of distance reduction, amelioration of misunderstandings and perceptions of isolation. The third factor represents perceptions of immediacy in dialogue. Immediacy represents temporal perceptions such as the accessibility of tutors and the affordance of the technology to enable reflection on learning or gaining quick responses.

Following the successful fit of the baseline face-to-face modality model, two additional pathway models were constructed to represent students' perceptions of communication with their tutors using email and telephone. Each was constructed 
with identical pathways, and tested individually for goodness of fit. Lagrange Multiplier (LM) tests were similarly performed on each model to ascertain the best fits for each.

\section{Discussion}

In this study, several parameters were taken into account including preferred approaches to study reported by students measured against the amount of structure, social presence and immediacy perceived by learners to have been present within each of the three tutor support modes. The three factors were constructed from items in the Communication Mode Questionnaire. Although the model was identified in faceto-face mode with a CFI of 0.92 and in telephone mode with a CFI of 0.94, the CFI for email mode was well below acceptable limits. However, after this model had been adjusted by convergence of two of the factors (surface and strategic approaches to study) into one (strategic), a more acceptable model CFI fit was obtained at 0.93.

The need to converge factors in email mode exposed an interesting effect relating to the nature of strategic study approaches. Convergence of the two factors was justified through a consideration of strategic learning approaches that embrace both deep and surface approaches. Students adopt strategic approaches depending upon the demands of the learning activity, switching between them according to need and expediency (Entwistle, 1981). It is plausible to surmise from the need to converge factors that students using email as a means to communicate with their remote tutors may rely more on strategic approaches to study than they do when they use more familiar telephone and face-to-face communication methods to access tutor support. They may need to adopt more flexible approaches to communication with their tutors due to the unfamiliar and less predictable nature of the technologies. The average age of students in the sample was 40.8 years, ensuring that the majority of participants in the study would not have used computer-based applications such as email at school, and would be less habituated in using them than the more familiar telephone. There may also be other variables influencing this result, such as the comparatively more limited access participants have to these new technologies, and the possibility of lack of technical skill and confidence in their effective use. The factor convergence adjustment will therefore be taken into account in this analysis of the three tutor support modalities.

It was important that, once a model fit had been established for the baseline face-to-face measurement model, the subsequent comparison models exhibited identical features including pathways, factors, and the same array of modality specific variables.

\section{Model parameters}

In this causal model, autonomous learners tend to perceive more rigidity or structure in their courses $(\beta=-0.37$, not significant) than their surface learner counterparts $(\beta$ $=-2.71$, not significant). Furthermore, as autonomous behaviour increases, so structural perceptions of the course will decrease. This result is expected, given that 
autonomous learners impose their own structure and therefore demand less structure from their tutors than surface learners. The strongest contributing measure to the surface factor is the need for precise study instructions $(\beta=0.52, p<0.05)$. Conversely the strongest item loading onto the autonomy factor is an item relating to students' need to control the learning process through self-organisation of time $(\beta=$ $0.76, p<0.05)$. This is the basis upon which this model and its companion models are founded. The central parameters are thus used as predictors of student responses in any given factor context.

For specific discussion of the models we explore immediacy in dialogue and how it may contribute toward a clearer understanding of the possible causes and effects of transactional distance.

\section{Immediacy}

As previously discussed, immediacy in this study refers to the extent to which students feel they can gain quick access to their tutors, and their perception of the timeliness of tutor responses. Immediacy is established in face-to-face settings through nodding, smiling and other non-verbal behaviours such as eye contact and gaze. It can also be characterised in paraverbal utterances such as backchannelling and other confirmatory utterances. Such behaviours are often subconsciously managed (Argyle \& Dean, 1965), but if they are absent or poorly mediated through the communication medium, students will notice. Immediacy also seems to at least partially to encompass the notion of the student's perception of 'connectedness' to the tutor as mediated through the appropriate technology, although this effect is perhaps better represented as a feature of social presence. Immediacy has been identified as an important measure of psychological distance, and could therefore be associated with perceived social presence in distance settings, as proposed by Argyle and Dean (1965). It is likely that a perception of lack of immediacy, resulting in a feeling of reduced social presence, may amplify the detrimental effects of transactional distance.

de Kerckhove (1997) suggests immediacy is an artefact of the increased capabilities of communication technologies to facilitate interaction. The ability, for example, of tutors to respond quickly or even 'instantly' to students' requests for help is extremely variable. If perceptions of immediacy can be increased or enhanced using technologymediated communication, however, we could surmise that face-to-face environments might take second place to that technology in the preferences of some students. If this were possible to achieve, it would represent the utopian ideal of distance learning actually surpassing the equivalency afforded by face-to-face learning (Simonson et al., 2000). Less variable would be the tutor's ability to respond quickly to provide feedback on a student's work, but sending a quick acknowledgement of receipt would still be possible and indeed even desirable (Collis \& Moonen, 2002) as a means of establishing some form of immediacy in the mind of the student. Either way, distance learners generally agree that immediacy of responses from their tutors encourages them to keep on track with their studies, and provides much needed impetus and 
motivation to persist with study. Indeed, timely responses and feedback from tutors may constitute the most significant predictor of distance learner satisfaction (Tallman, 1994).

Immediacy may also directly influence feelings of intimacy in relationship building between student and tutor. Gunawardena (1995) has argued that immediacy can convey closeness and 'warmth', while lack of immediacy often connotes aloofness or 'coldness' (Wallace, 1999), indicating that there is a clear relationship between immediacy and intimacy. Gunawardena and Zittle (1997) also connect intimacy and social presence, arguing they are measures of the amount of 'psychological distance that a communicator puts between him or herself and the object of his/her communication' (p. 9). Gunawardena and Zittle consider that tutors can convey this intimacy as an immediacy of communication through both verbal and non-verbal means, the latter usually through dress codes, facial expressions, and so on. Patently, such non-verbal expressions of immediacy are best conveyed through communication in face-to-face mode. Immediacy can be a feature of either the communications technology itself or the skills and attributes of the communicator (Short et al., 1976; Whittaker, 1996). It is of course entirely possible that immediacy may be an artefact of both the individual's skills and the affordance of the technology. Notwithstanding this discussion, immediacy should be considered an important predictor of student satisfaction, and could also therefore be deemed a key predictor of transactional distance.

It is apparent from the results of the structural equation modelling of the modality hypothesis that out of the communication modes email is associated with the greatest perception of immediacy of response from the tutor for autonomous students at $\beta=$ $0.49, p=0.00001$ (Table 2). This result runs counter to hypothesis two, and is a somewhat surprising finding, being the only asynchronous communication modality chosen for analysis within this study. However, if de Kerckhove and others are correct, and technology-mediated communication has the capability to enhance communication characteristics such as immediacy, this finding makes sense.

There is a caveat to this finding, however. This result could be confounded by the inclusion of the 'time to reflect' questionnaire item within this factor. Time to reflect is important for many students, particularly those who approach study in a less impulsive manner. Students who need time to reflect may prefer the asynchronous affordance of communication through email when compared with synchronous modes of communication such as the telephone. The presence of the 'time to reflect' item within the immediacy factor may be a misleading element. Future questionnaire design would need to take into account the possibility that there may be two separate aspects of immediacy that influence a student's perception of how quickly the tutor responds. It is probable that immediacy of tutor response and the ability to defer immediate response in favour of greater time for reflection are two separate constructs.

These results may also be due to an increased usage of email to communicate in recent times, with the telephone being relegated to second place in the working life of many. Longer, more detailed, email messages can be composed and sent, and there is the facility for tutors to program automatic acknowledgements of message receipt 
into their systems. Email use can also be creative, providing users with a rich repertoire of text-based expressions, emoticons and other devices with which to communicate (Wheeler \& Nistor, 2003). Such variables should be acknowledged in any analysis of this type.

Both the student autonomy $(\beta=0.49, z=9.457, p=0.00001)$ and strategic approaches to study factors $(\beta=0.77, z=4.542, p=0.00001)$ for email mode show statistically significant beta coefficients. These results indicate that students who can direct their own study will perceive more immediacy from email communication than their less autonomous counterparts. Furthermore, those who are able to approach their learning in a strategic, flexible and versatile manner will perceive greater levels of immediacy in email-mediated communication. Similarly with students who need more time to contemplate their learning, the findings suggest that students scoring high in personal autonomy tend to see email as offering a more effective facility with which to reflect upon the learning process. They may also view it as a better utility through which to receive valid and more considered tutor responses in comparison with other modes of communication. The affordance of permanency of email through archiving may advance dialogue beyond real-time events for these students.

Strategic learners within the sample may also consider that email provides greater accessibility to the remote tutor than other modes of communication. Co-present interactions can be rushed or deferred due to pressure of time, environmental distraction or other communication constraints. Email communication would not be directly affected by these constraints. Further research into these possibilities should be considered as this is perhaps one area in which distance students might regularly benefit over their traditional on-campus counterparts.

Students receiving timely tutor responses by email could be more predisposed to perceptions of immediacy than those who experienced longer waits. Another factor worthy of consideration is the perceived urgency or importance of the message sent by the student to the tutor. If students perceive that messages they have sent to their tutors are urgent, yet they receive no response, or they receive a response they consider to be unduly delayed, more remote transactional distance may be experienced than if they perceived their messages to be less urgent. Transactional distance could also be a function of the students' perceptions of the urgency or importance of their message, regardless of the media or technology used to mediate the communication process. Asynchronous communication systems such as email should therefore fare less well than synchronous systems as a means of conveying urgent messages.

\section{Social presence}

This study investigated the link between transactional distance and social presence. Similarly to transactional distance, social presence is a perceived aspect of technology-mediated communication, and both are hypothesised to have their basis in dialogic processes, so the theoretical basis seems feasible.

As social presence is indicative of feelings of connectedness, less autonomous students who are more dependent on their tutors should seek higher levels. However, 


\section{S. Wheeler}

in this sample, a significant finding is observed for autonomous learners. An examination of the results shown in the summary of coefficients in Table 2 reveals that the email communication yields the steepest beta coefficient for autonomous learner perceptions of social presence $(\beta=0.31, p<0.05)$. This result runs counter to hypothesis two, supporting earlier findings of increased perception of immediacy within email mode.

Autonomous students in the sample may have perceived face-to-face conversation with their tutor to be dialogically the poorest, thereby engendering a more remote transactional distance. Due to their high levels of autonomous behaviour, such students may be more comfortable studying remotely from their tutors, preferring to communicate in a manner that enables them to maintain a level of control. Email certainly provides such learner centric affordances. Conversely, surface studiers reported much lower levels of social presence in telephone mode $\beta=-1.45$, not significant) and much higher levels of social presence face to face $(\beta=2.98$, not significant). This result is more in line with expectations, given that surface learners tend to rely more on direct instruction and tutor feedback than their more autonomous peers. Communication over telephone would therefore be less preferable for surface learners than a face-to-face tutorial. However, these results should be treated with some caution, as the beta coefficients are statistically non-significant.

This result appears to support the earlier finding that immediacy was perceived by participants to be higher in email mode. Although the two are associated, perhaps a distinction between immediacy and perceived social presence should be clarified. Immediacy has already been defined as relating to the learner perception of connectedness and accessibility to the tutor. It also has elements of reflection on learning and is therefore essentially temporal. Conversely, social presence focuses more on the affordances of the communicating medium, and perceptions that the student is communicating with a real person rather than with a mute technology. Social presence defines the qualitative difference between students being able to communicate their needs from a distance, thereby reducing social isolation, as opposed to the ease of accessing tutor support and the gaining of quick response times. Characterising two distinct aspects of dialogue in the form of immediacy and social presence may be helpful to determine its function in transactional distance better.

\section{Structure}

Structure has been defined as the extent of the constraints imposed upon students through the way a course is delivered, managed and evaluated. In this context, study can be characterised by its level of flexibility or rigidity. Lower levels of structure were reported by strategic learners in telephone mode than in other modes $(\beta=0.92, z=$ 2.671, $p=0.003$ ), with the highest levels of structure being reported in face-to-face contexts $(\beta=2.61, z=1.503, p=0.06$, not significant). Students therefore reported more flexibility in telephone mode than in face-to-face contact with their tutors. While the face-to-face result should be treated with caution, the finding in telephone mode is statistically significant and suggests that this mode of communication may 
impose a lesser level of structure upon strategic distance learners than any of the other modes. This is possibly due to an increase in the dialogue that is inherent in telephone communication. If Moore's transactional distance theory is correct, the telephone should produce the least transactional distance for strategic distance learners due to its greater potential to reduce structure. Telephone-mediated dialogue may subvert structure due to its often informal and open-ended nature. It should also be noted that the telephone is probably the most easily accessible and familiar of the technologies for the majority of the participants.

Analysis of email communication also yielded a statistically significant positive regression $(\beta=0.98, p<0.05)$ from strategic approaches to structure, which suggests that this technology would actually impose greater levels of structure for strategic distance learners. If Moore's theory is correct, email would actually create a more remote transactional distance for strategic learners than other modes of communication, with the telephone emerging as the technology that is least likely to impose structure.

In the original modality hypothesis, co-present tutorials were predicted to evoke the least amount of reported transactional distance, on the basis that the level of dialogue would be richer. If dialogue is richer in face-to-face communication, then close transactional distance would be experienced; while if high levels of structure were imposed, remote transactional distance would result. It is clear from an examination of the covariance matrix that face-to-face mode is actually one of the most effective modes in imposing structure upon strategic distance learners $(\beta=2.15, z=1.484, p$ $=0.06$, not significant). Some autonomous learners in the sample may have been able to subvert the structural effects of the face-to-face encounter more effectively than in most of the other communication modes $(\beta=-0.37, z=-0.602, p=0.27$, not significant). Autonomous learners may have achieved this by proactively instigating more dialogue with their remote tutors, which would decrease structure. However, this is conjectural as, again, these results were far from conclusive and yielded no statistical significance.

What also remains unresolved is whether the imposed structure on study actually increases transactional distance. Many commentators suggest that this is the case, but doubt remains (Vrasidas \& McIsaac, 1999), and there is also a dearth of concerted research into this effect within multiple-mode learning environments. It may be beneficial to approach this problem by viewing structure, perception of social presence and immediacy as three separate constructs, each of which may contribute toward transactional distance. Moore's original configuration of structure and dialogue remains intact, but with dialogue consisting of at least two subfactors, social presence and immediacy. These are therefore proposed as revised predictors of transactional distance.

\section{Conclusions}

There are several limitations to this study. Firstly, the opportunistic sample comprised several cohorts of students studying in a variety of blended modes, at various levels 
from foundation degree to postgraduate study. The statistical method was not designed to investigate the nuances and subtleties of individual student experiences across such a range of levels. Secondly, the mix of communication modes provides little knowledge about student perceptions for those who engaged in both modes of distance communication. It would be unwise to attempt to generalise these findings across all blended learning experiences, but the results nonetheless raise some interesting issues.

Statistically significant findings related mainly to autonomous and strategic learners. Email seems to provide the highest level of immediacy of dialogue for learners who are proactive and who control their own learning activities $(p=0.00001)$. Email also provides the greatest amount of social presence for autonomous students $(p<0.05)$. However, email is also likely to impose the highest amount of structure on strategic learners, and if this is at the expense of dialogue then it is likely to create a more remote transactional distance for this type of learner $(p<0.05)$. Finally, the telephone tends to impose the least amount of structure on strategic learners $(p<$ 0.05), which may lessen transactional distance.

It can be concluded from these findings that students experience at least some elements of transactional distance when separated from their tutors. Structure can be imposed by communication technologies to varying degrees, with the telephone appearing to produce the lowest level. Dialogue can be mediated through a variety of technologies but for this sample email appears to facilitate the highest levels of immediacy, and so should be considered an important communication technology for tutors to develop within any blended learning strategy. The future success of blended learning will rely heavily on technology-mediated communication, but even more on the skills and knowledge of responsive tutors.

\section{References}

Argyle, M. \& Dean, J. (1965) Eye contact, distance and affiliation, Sociometry, 28, 289-304.

Byrne, B. M. (1994) Structural equation modeling with EQS and EQS for Windows: basic concepts, applications and programming (London, Sage).

Collis, B. \& Moonen, J. (2002) Flexible learning in a digital world: experience and expectation (London, Kogan Page).

Dabbagh, N. (2004) Distance learning: emerging pedagogical issues and learning designs, Quarterly Review of Distance Education, 5(1), 37-49.

de Kerckhove, D. (1997) The skin of culture: investigating the new electronic reality (London, Kogan Page).

Dron, J., Seidel, C. \& Litten, G. (2004) Transactional distance in a blended learning environment, ALT-f: Research in Learning Technology, 12(2), 163-174.

Entwistle, N. J. (1981) Styles of learning and teaching (Chichester, John Wiley \& Sons).

Goodyear, P., Asensio, M., Jones, C., Hodgson, V. \& Steeples, C. (2003) Relationships between conceptions of learning, approaches to study and students' judgements about the value of their experiences of networked learning, ALT-F: Research in Learning Technology, 11(1), 17-27.

Gunawardena, C. N. (1995) Social presence theory and implications for interaction and collaborative learning in computer conferencing, International fournal of Educational Telecommunications, $1(2 / 3), 147-166$. 
Gunawardena, C. N. \& Zittle, F. J. (1997) Social presence as a predictor of satisfaction within a computer-mediated conferencing environment, The American fournal of Distance Education, $11(3), 8-26$.

Miyake, A., Friedman, N. P., Emerson, M. J., Witzki, A. H., Howerter, A. \& Wager, T. D. (2000) The unity and diversity of executive functions and their contributions to complex 'frontal lobe' tasks: a latent variable analysis, Cognitive Psychology, 41, 49-100.

Moore, M. G. (1973) Towards a theory of independent learning and teaching, fournal of Higher Education, 44(12), 661-679.

Moore, M. G. (1993) Theory of transactional distance, in: D. Keegan (Ed.) Theoretical principles of distance education (New York, Routledge), 22-38.

Moore, M. G. \& Kearsley, G. (1996) Distance education: a systems view (Belmont, CA, Wadsworth).

Ross, S. M., Morrison, G. R., Smith, L. J. \& Cleveland, E. (1991) An evaluation of alternative distance tutoring models for at-risk elementary school children (ERIC Document Reproduction Service No. ED 335 009).

Shin, N. (2003) Transactional presence as a critical predictor of success in distance learning, Distance Education, 24(1), 69-86.

Short, J., Williams, E. \& Christie, B. (1976) The social psychology of telecommunications (London, John Wiley).

Simonson, M., Smaldino, S., Albright, M. \& Zvacek, S. (2000) Teaching and learning at a distance: foundations of distance education (Upper Saddle River, NJ, Merrill).

Simpson, O. (2004) The impact on retention of interventions to support distance learning students, Open Learning, 19(1), 79-95.

Tallman, F. D. (1994) Satisfaction and completion of correspondence study: the influence of instructional and student-support services, The American fournal of Distance Education, 8(2), 43-57.

Vrasidas, C. \& McIsaac, M. S. (1999) Factors influencing interaction in an online course, The American Fournal of Distance Education, 13(3), 22-26.

Wallace, P. M. (1999) The psychology of the internet (Cambridge, Cambridge University Press).

Weinstein, C. E. \& Van Mater Stone, D. (1996) Learning strategies and learning to learn, in: E. de Corte \& F. E. Weinert (Eds) International encyclopedia of developmental and instructional psychology (Oxford, Pergamon), 419-423.

Wheeler, S. (2002) Student perceptions of support in distance education, Quarterly Review of Distance Education, 3(4), 419-429.

Wheeler, S. \& Nistor, N. (2003) Human behaviour in the online sub culture, in: N. Nistor, S. English, S. Wheeler \& M. Jalobeanu (Eds) Toward the virtual university: international online perspectives (Greenwich, Information Age).

Wheeler, S. \& Vranch, A. T. (2001) Building for the future of educational telematics: models, foundations and frameworks, International fournal of Engineering Education, 17(2), 145-152.

Whittaker, S. (1996) Talking to strangers: an evaluation of the factors affecting electronic collaboration, in: Proceedings of Conference on Computer Supported Collaborative Work (New York, ACM Press), 409-418. 